\begin{tabular}{|c|c|c|}
\hline \multirow{3}{*}{ 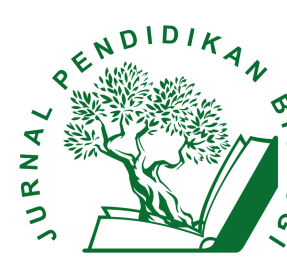 } & Jurnal Pendidikan Biologi 8 (1) (2018) 1 - 5 & 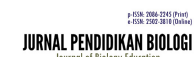 \\
\hline & Jurnal Pendidikan Biolog & \\
\hline & $\frac{\text { http://jurnal.unimed.ac.id/2012/index.php/JPB }}{\text { eISSN: } 2502-3810 \text { pISSN: } 2086-2245}$ & $=$ \\
\hline
\end{tabular}

\title{
Pengaruh Model Problem Basic Learning Dengan Teknik Mind Mapping Terhadap Kemampuan Berpikir Kritis dan Pengetahuan Metakogitif Siswa Sekolah Menengah Pertama
}

\author{
Chintani Sihombing, Deswidya Sukrisna Hutauruk, Salim Efendi \\ Universitas Efarina, Kampus II, Jl. Sudirman No.8 Pematangsiantar, Pematang siantar, Indonesia
}

\section{INFO ARTIKEL}

\section{Histori Artikel}

Received 26 Oktober 2018

Revised 13 Nopember 2018

Accepted 26 Nopember 2018

Published 3 Desember 2018

Keywords:

Critical thinking ability, Metacognitive Knowledge,

Problem Based Learning

\begin{abstract}
The research was conducted aimed at knowing the effect of the Problem Based Learning model with Mind Mapping techniques influencing critical thinking skills and metacognitive knowledge of junior high school students. The sample of this study was class IX in SMP Negeri 1 Ronggur Nihuta which was taken by random sampling with the number of students 62. The instrument of this research was a test. This research method is descriptive and data analysis techniques using the $t$ test with a significance level $\alpha=0.05$. The results showed that the influence of the Problem Based Learning model with Mind Mapping techniques had an effect on students' critical thinking skills ( $t_{\text {count }} 90.66>t$ table 2.039 ); (2) There is the influence of the Problem Based Learning model with the Mind Mapping technique affecting the metacognitive knowledge of students ( $t$ count $40.68>t$ table 2.039). The results of this study imply that the level of critical thinking skills, metacognitive knowledge has an important role in improving the learning outcomes of junior high school students.
\end{abstract}

Copyright (C) 2018 Universitas Negeri Medan. Artikel Open Access dibawah lisensi CC-BY-4.0 (https://creativecommons.org/licenses/by/4.0)

How to Cite

Sihombing, C., Hutauruk, D. S., \& Efendi, S. (2018). Pengaruh Model Problem Basic Learning Dengan Teknik Mind Mapping Terhadap Kemampuan Berpikir Kritis dan Pengetahuan Metakogitif Siswa Sekolah Menengah Pertama. Jurnal Pendidikan Biologi, 8(1), 1-5.

\section{PENDAHULUAN}

Dimensi pengetahuan, siswa diharapkan memiliki pengetahuan faktual, konseptual, prosedual dan metakognitif. Dimensi keterampilan siswa diharapkan memiliki kemampuan berpikir dan tindak yang efektif dan kreatif. Pelajaran biologi merupakan pengetahuan faktual, konseptual, dan prosedural. Dalam pembelajaran siswa diharuskan mampu melakukan proses penemuan dan sikap ilmiah (Puspita et al., 2012), sehingga siswa harus mampu berpikir kritis dalam proses pembelajaran yang didukung oleh seorang guru.

Kemampuan berpikir kritis merupakan kemampuan yang harus dimiliki oleh siswa. Berpikir kritis telah terbukti untuk mempersiapkan siswa dalam berpikir dalam berbagai disiplin ilmu karena berpikir kritis merupakan kegiatan kognitif yang dilakukan siswa yang fokus pada pembuatan keputusan 
dengan apa yang dilakukan dengan cara membagi-bagi cara berpikir dalam kegiatan nyata (Sudiarta, 2009). Pengetahuan metakognitif siswa juga belum dievaluasi secara maksimal. Instrumen penilaian (soal dan tugas) yang diberikan guru pada umumnya di aspek kognitif. Ruang untuk metakognitif yaitu evaluasi mulai dari merencanakan, melaksanakan, dan refleksi kesulitan yang dialami saat belajar kurang diberdayakan. Akibatnya kita tidak tahu apakah siswa telah menggunakan proses metakognitifnya atau belum bahkan mungkin mereka tidak sadar bahwa mereka memiliki metakognitif.

Siswa yang tidak memiliki keterampilan metakognitif yang baik tidak bisa memprediksi kelebihan dirinya dan tidak mempunyai perencanaan memilih bidang studi/Jurusan di Sekolah Menengah Atas bahkan sampai ke perguruan tinggi yang sesuai dengan minatnya. Mind maping yang diberikan dapat memberikan gambaran dari materi yang luas, merangkum materi pembelajaran yang telah dipelejari dan memasukkan informasi ke dalam ingatan siswa. Mind Mapping diterapkan untuk penanaman konsep dan meningkatkan pemahaman konsep biologi agar siswa lebih mudah dalam mengingat materi yang telah diajarkan, dengan Mind Mapping siswa mampu mengkonstruksi kembali informasi-informasi yang telah diperoleh (Firdaus, 2010).

Berdasarkan latar belakang yang telah dijelaskan diatas, maka tujuan dari penelitian ini adalah untuk mengetahui pengaruh model pembelajaran Problem Based Learning dengan teknik Mind Mapping terhadap kemampuan kritis dan pengetahuan metakognitif siswa Sekolah Menengah Pertama. Penelitian ini diharapkan dapat menjadi informasi penting dalam upaya meningkatkan kemampuan berpikir kritis dan metakognitif siswa di Sekolah Menengah Pertama.

\section{METODE}

Penelitian ini dilaksanakan di SMP Negeri 1 Ronggur Nihuta, Kabupaten Samosir, Sumatera Utara. Pengambilan sampel dilakukan dengan cara simple random sampling dimana setiap kelas memiliki kesempatan yang sama untuk menjadi sampel penelitian. Sampel kelas diambil sebanyak 2 kelas secara acak sehingga diperoleh satu kelas diberi pengajaran dengan model Pembelajaran Berbasis Masalah dengan teknik Mind Mapping dan kelas lainnya diberi pengajaran dengan model Pembelajaran Konvensional.

Analisisnya dilakukan uji normalitas dengan menggunakan uji Kolmogorov-Smirnov Test Mengunakan program SPSS 20.0 For Windows dengan Kriteria pengujian adalah Signifikan $>\alpha(0,05)$ maka data terdistribusi normal. Untuk mengetahui apakah data berasal dari populasi yang bervarians sama (homogen) digunakan uji Levene Statistic pada taraf signifikansi 0,05 . Teknik analisis data dengan menggunakan uji $t$ dengan taraf signifikan $\alpha=0,05$.

\section{HASIL DAN PEMBAHASAN}

Berdasarkan hasil penelitian terdapat perbedaan kemampuan bertpikir kritis dari kedua kelas. Setelah dilakukan pembelajaran problem based learning maka hasil pretest mengalami peningkatan (Tabel.1). 
Tabel 1. Kemampuan berpikir Kritis siswa

\begin{tabular}{ccccc}
\hline Data & \multicolumn{2}{c}{ Pretest } & \multicolumn{2}{c}{ Postest } \\
\cline { 2 - 5 } & Kelas Eksperimen & Kelas Kontrol & Kelas Eksperimen & Kelas Kontrol \\
\hline N & 32 & 30 & 32 & 30 \\
Maks & 75 & 70 & 97 & 75 \\
Min & 55 & 50 & 80 & 55 \\
X & 62,69 & 59,53 & 88,06 & 62,87 \\
SD & 11,01 & 10,92 & 10,63 & 10,15 \\
\hline
\end{tabular}

Berdasarkan hasil uji hipotesis berbasis masalah (Problem Based Learning) menunjukkan bahwa nilai $t_{\text {hit }}$ lebih besar dari merupakan salah satu model pembelajaran $t_{\text {tab }}(90.66>2,039)$ maka $H_{a}$ diterima yang yang berasosiasi dengan pembelajaran menyatakan bahwa terdapat pengaruh model kontekstual. Hasil penelitian Masek \& Yamin problem based learning dengan teknik Mind (2011) menemukan bahwa keterampilan Mapping terhadap kemampuan berpikir kritis berpikir kritis peserta didik mengalami siswa (Tabel 2). Model pembelajaran problem peningkatan setelah melakukan model based learning menekankan keaktifan siswa pembelajaran Problem Based Learning. Mempreuntuk mengemukakan, menemukan dan sentasikan gagasannya, mengkomuni-kasikan memecahkan masalah pengetahuan. merupakan latihan siswa untuk meningkatkan Husnidar, et al. (2014) bahwa pembelajaran kemampuan berpikir kritis.

Tabel 2. Hasil Uji t Kemampuan Berpikir Kritis

\begin{tabular}{cccccc}
\hline \multirow{2}{*}{$\mathbf{T}$} & \multirow{2}{*}{$\mathbf{d b}$} & \multirow{2}{*}{ Signifikansi } & \multirow{2}{*}{ Mean berbeda } & \multicolumn{2}{c}{ Interval yang berbeda } \\
\cline { 5 - 6 } & & & & Lebih Rendah & Lebih Tinggi \\
\hline 90,665 & 31 &, 000 & 88,063 & 86,08 & 90,04 \\
\hline
\end{tabular}

Kemampuan berpikir kritis siswa yang berkembang dengan membiasakan untuk berpikir dengan penggunaan model problem based learning (Sadia, 2008). Model Problem based learning dengan teknik Mind Mapping mengajak siswa untuk dapat berperan langsung dalam proses pembelajaran, menyampaikan kreativitas. Hal tersebut sesuai dengan pernyataan Naim (2009), model pembelajaran dengan teknik Mind Mapping maka suasana belajar dapat lebih efektif karena melibatkan siswa secara langsung sehingga siswa merasa tertarik.

Pengetahuan metakognitif siswa terdapat perbedaan rata-rata pretest kelas eksperimen dan kelas kontrol masing-masing 22,24 dan 17,99. Pengetahuan metakognitif lebih besar pada kelas eksperimen daripada kelas kontrol. Hasil post test pada kelas eksperimen dan kelas kontrol masing-masing yaitu 75,05 dan 25,13 (Tabel 3).

Tabel 3. Pengetahuan Metakognitif Siswa

\begin{tabular}{ccccc}
\hline & \multicolumn{2}{c}{ Pretest } & \multicolumn{2}{c}{ Postest } \\
\cline { 2 - 5 } & Kelas Eksperimen & Kelas Kontrol & Kelas Eksperimen & Kelas Kontrol \\
\hline N & 32 & 30 & 32 & 30 \\
Maks & 38 & 31 & 94 & 62 \\
Min & 4 & 5 & 52 & 8 \\
X & 22,24 & 17,99 & 75,05 & 25,13 \\
SD & 8,791 & 8,070 & 10,436 & 11,549 \\
\hline
\end{tabular}


Hasil uji hipotesis pengetahuan metakognitif, menunjukkan bahwa nilai $t_{\text {hit }}$ lebih besar dari $\mathrm{t}_{\text {tab }}(40.68>2,039)$ maka $\mathrm{H}_{\mathrm{a}}$ yang menyatakan bahwa terdapat pengaruh model problem based learning dengan teknik Mind Mapping terhadap pengetahuan metakognitif siswa. Hasil penelitiin ini sama halnya dengan penelitian Lina Gassner (2009) bahwa model PBL berpengaruh secara langsung dalam meningkatkan kesadaran metakognitif siswa dimana model ini mengharuskan siswa berpikir mengenai pengetahuan apa dan mengapa dalam memecahkan masalah. Brian Wacaksono, et al., 2013 juga menyimpulkan dalam penelitiannya model PBL meningkatkan kemampuan metakogntif siswa sehingga dapat meningkatkan hasil belajar siswa dan dengan kemampuan metakognitif pada siswa dapat meningkatkan hasil pengetahuan metakognitif siswa. Model pembelajaran problem based learning dengan teknik Mind Mapping dapat memberdayakan metakognitif siswa dengan melibatkan siswa untuk aktif dan mampu untuk memecahkan masalah dengan bekerja kelompok (Sa'adah, 2015).

Tabel 4. Hasil Uji t Pengetahuan Metakognitif

\begin{tabular}{cccccc}
\hline \multirow{2}{*}{$\mathbf{T}$} & $\mathbf{d b}$ & Signifikansi & \multirow{2}{*}{ Mean berbeda } & \multicolumn{2}{c}{ Interval yang berbeda } \\
\cline { 5 - 6 } & & & & Lebih Rendah & Lebih Tinggi \\
\hline 40,686 & 31 &, 000 & 75,060 & 71,30 & 78,82 \\
\hline
\end{tabular}

Adanya pengaruh pengetahuan metakognitif setelah diterapkan model PBL dengan teknik Mind Mapping. Berdasarkan hasil penelitian yang dilakukan oleh Lina Gassner (2009) tentang model pembelajaran PBL berpengaruh terhadap kesadaran metakognitif siswa. Kesadaran metakognitif pada model pembelajaran PBL mengajak siswa untuk memecahkan masalah yang diberikan guru. Simamora (2012) menyatakan bahwa siswa SMP sudah mencapai tahap perkembangan berpikir logis, yaitu kemampuan menyusun rencana untuk memecahkan masalah. Keterampilan ini dapat membantu siswa mengambil keputusan yang tepat, cermat, sistematis, logis, dan mempertimbangkan berbagai sudut pandang. Pembelajaran dengan pendekatan metakognitif pada siswa Sekolah Menengah pertama juga dapat membuat siswa berfikir tentang perencaaan kerja hingga pemecahan masalah (Patonah, 2014).

\section{KESIMPULAN}

Berdasarkan hasil penelitian yang telah dilakukan, maka diperoleh bahwa model problem based learning dengan teknik Mind Mapping berpengaruh terhadap kemampuan berpikir kritis dengan nilai thit lebih besar dari $t_{\text {tab }}(90.66>2,039)$. Pengaruh model Problem Based Learning dengan teknik Mind Mapping terhadap pengetahuan metakognitf dengan nilai $t_{\text {hit }}$ lebih besar dari $t_{\text {tab }}(40.68>2,039)$. Membiasakan siswa untuk sering menggunakan kemampuan berpikir kritis dengan teknik Mind Mapping diterapkan untuk penanaman konsep dan meningkatkan pemahaman konsep biologi agar siswa lebih mudah dalam mengingat materi yang telah diajarkan. Siswa juga mengetahui pengetahuan metakognitif siswa dengan model problem basic learning. 


\section{DAFTAR PUSTAKA}

Firdaus, W. (2010). Uji coba metode mind mapping untuk meningkatkan kemampuan membaca sekilas (skimming). Jurnal UPI dan UPSI Bandung, 4(2), 356-365.

Gassner, L. (2009). Developing Metacognitive Awareness- a modified model of a PBL Tutorial. Bachelor Thesis of Odontology in Oral Health. Malmö University

Husnidar, Ikhsan, M., \& Rizal, S. (2014). Penerapan Model Pembelajaran Berbasis Masalah untuk Meningkatkan Kemampuan Berpikir Kritis dan Disposisi Matematika Siswa. Jurnal Didaktik Matematika, 1(1), 71-82.

Masek, A., \& Yamin. S. (2011). The effect of Problem Based Learning on Critical Thinking Ability. International Review of Social Sciences and Humanities. 2(1), 215-221.

Naim, M. (2009). Penerapan metode quantum learning dengan teknik peta pikiran (Mind Mapping) dalam pembelajaran fisika. Jurnal Ilmiah Kreatif 6 (1), 82-100.

Patonah, S. (2014). Elemen Bernalar Tujuan pada Pembelajaran IPA Melalui pendekatan Metakognitif Siswa SMP. Jurnal Pendidikan IPA Indonesia, 3(2): 128-133

Puspitasari, D., \& Hardini, I. (2012). Strategi Pembelajaran Terpadu. Yogyakarta: Familia

Sa'adah, L.S. (2015). Pengaruh model pembelajaran Problem based learning terhadap keterampilan metakognisi, berpikir kritis, dan argumentasi ilmiah siswa kelas VIII SMP Pawiyatan Daha 2 Kediri materi sistem pernapasan manusia. Seminar Nasional Pendidikan Biologi FKIP UNS

Sadia, I.W. (2008). Model pembelajaran yang efektif untuk meningkatkan keterampilan berpikir kritis (suatu persepsi guru). Jurnal Pendidikan dan Pengajaran UNDIKSHA. 41 (2), 219-237.

Simamora, M. (2014). Analisis Kemampuan Metakognisi Siswa dalam Pembelajaran Biologi Melalui Assesmen Pemecahan Masalah di SMA NEGERI 5 Kota Jambi. Jurnal Penelitian Kependidikan FKIP Universitas Jambi. 1-19

Sudiarta, I.G. (2009). Pengembangan pembelajaran berpendekatan tematik berorientasi pemecahan masalah matematika terbuka untuk mengembangkan kompetensi berpikir divergen, kritis, dan kreatif. Jurnal Pendidikan dan Pengajaran UNDIKSHA. 2 (4), 373-392.

Wicaksono, R., Akhdinirwanto, W.R., \& Ashari. (2013). Peningkatan Kemampuan Metakognitif Fisika Melalui Model Pembelajaran Problem Based Learning Pada Smk Pancasila 1 Kutoarjo. Jurnal Radiasi. 3 (2), 182-185. 